\title{
Correction to: YPEL3 suppresses epithelial- mesenchymal transition and metastasis of nasopharyngeal carcinoma cells through the Wnt/ $\beta$-catenin signaling pathway
}

Jian Zhang ${ }^{\dagger}$, Xin Wen ${ }^{\dagger}$, Xian-Yue Ren, Ying-Qin Li, Xin-Ran Tang, Ya-Qin Wang, Qing-Mei He, Xiao-Jing Yang, Ying Sun, $\mathrm{Na} \mathrm{Liu}^{*}$ and Jun Ma*

\section{Correction to: J Exp Clin Cancer Res 35, 109 (2016)}

https://doi.org/10.1186/s13046-016-0384-1

Following publication of the original article [1] and subsequent correction [2], the authors identified that further mismatched images were present in the corrected version of Fig. 3. Specifically, in Fig. 3, the SUNE1-si974 cells at $0 \mathrm{~h}$ (Si-NC and Si-974) were incorrect, and have been replaced by the correct images.

In addition, the figures 2,3 , and 6 in the previous correction [2] were not replaced in the original article [1], thus, the figure 2 and 6 have been replaced together with figure 3.

The corrected figure is given here. The correction does not affect the conclusions of the article. The original article has been updated.
References

1. Zhang J, Wen $X$, Ren XY, et al. YPEL3 suppresses epithelial-mesenchymal transition and metastasis of nasopharyngeal carcinoma cells through the Wnt/ß-catenin signaling pathway. J Exp Clin Cancer Res. 2016;35:109. https://doi.org/10.1186/s13046-016-0384-1.

2. Zhang J, Wen X, Ren XY, et al. Correction to: YPEL3 suppresses epithelialmesenchymal transition and metastasis of nasopharyngeal carcinoma cells through the Wnt/ $\beta$-catenin signaling pathway. J Exp Clin Cancer Res. 2020;39:214. https://doi.org/10.1186/s13046-020-01710-y.

Published online: 23 December 2021

\footnotetext{
*Correspondence: liun1@sysucc.org.cn; majun2@mail.sysu.edu.cn

${ }^{\dagger}$ Jian Zhang and Xin Wen contributed equally to this work.

Sun Yat-sen University Cancer Center; State Key Laboratory of Oncology in South China, Collaborative Innovation Center of Cancer Medicine, 651

Dongfeng Road East, Guangzhou, People's Republic of China
}

(c) The Author(s) 2021. Open Access This article is licensed under a Creative Commons Attribution 4.0 International License, which permits use, sharing, adaptation, distribution and reproduction in any medium or format, as long as you give appropriate credit to the original author(s) and the source, provide a link to the Creative Commons licence, and indicate if changes were made. The images or other third party material in this article are included in the article's Creative Commons licence, unless indicated otherwise in a credit line to the material. If material is not included in the article's Creative Commons licence and your intended use is not permitted by statutory regulation or exceeds the permitted use, you will need to obtain permission directly from the copyright holder. To view a copy of this licence, visit http://creativecommons.org/licenses/by/4.0/. The Creative Commons Public Domain Dedication waiver (http://creativeco mmons.org/publicdomain/zero/1.0/) applies to the data made available in this article, unless otherwise stated in a credit line to the data. 
a

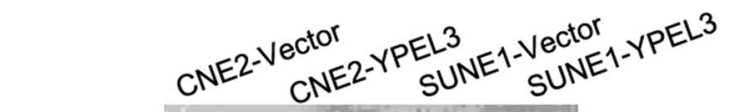

HA-YPEL3

GAPDH

b
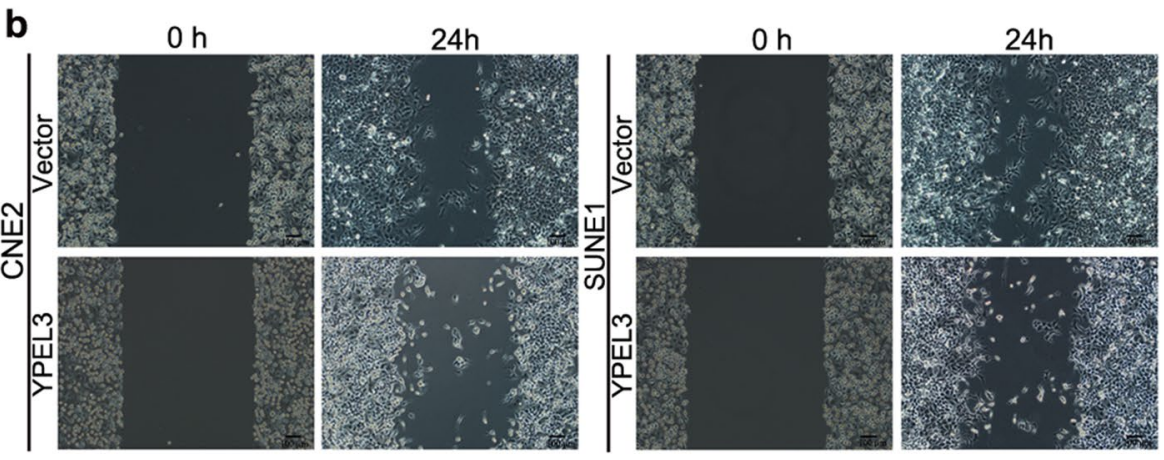

c

YPEL3
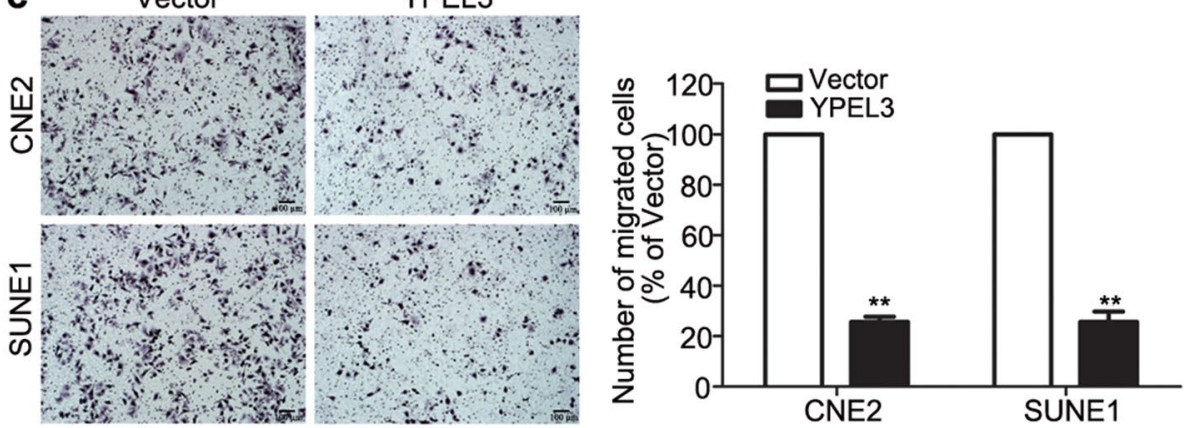

d

Vector
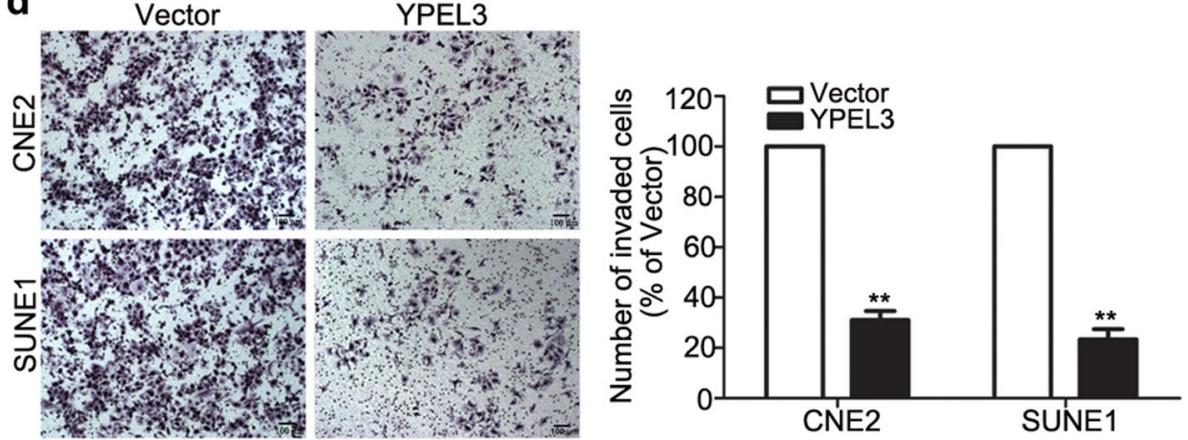

Fig. 2 Effects of YPEL3 overexpression on NPC cell migration and invasion in vitro. a Representative western blotting analysis of YPEL3 overexpression in CNE-2 and SUNE-1 cells. GAPDH served as the loading control. $\mathbf{b}$-d Representative images and quantification of the effects of YPEL3 overexpression on the migratory and invasive abilities of CNE-2 and SUNE-1 cells as determined by wound healing (b), Transwell migration (c), and invasion (d) assays. All of the experiments were performed at least three times. Data presented are the mean \pm SD; ${ }^{* *} P<0.01$ compared with control using Student t-test 
a

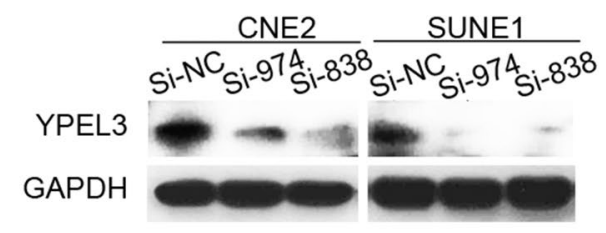

b

$\mathrm{Oh}$

$24 \mathrm{~h}$

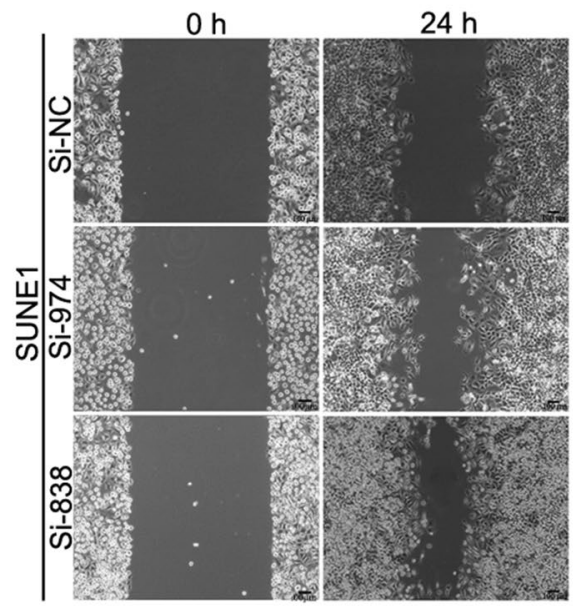

C
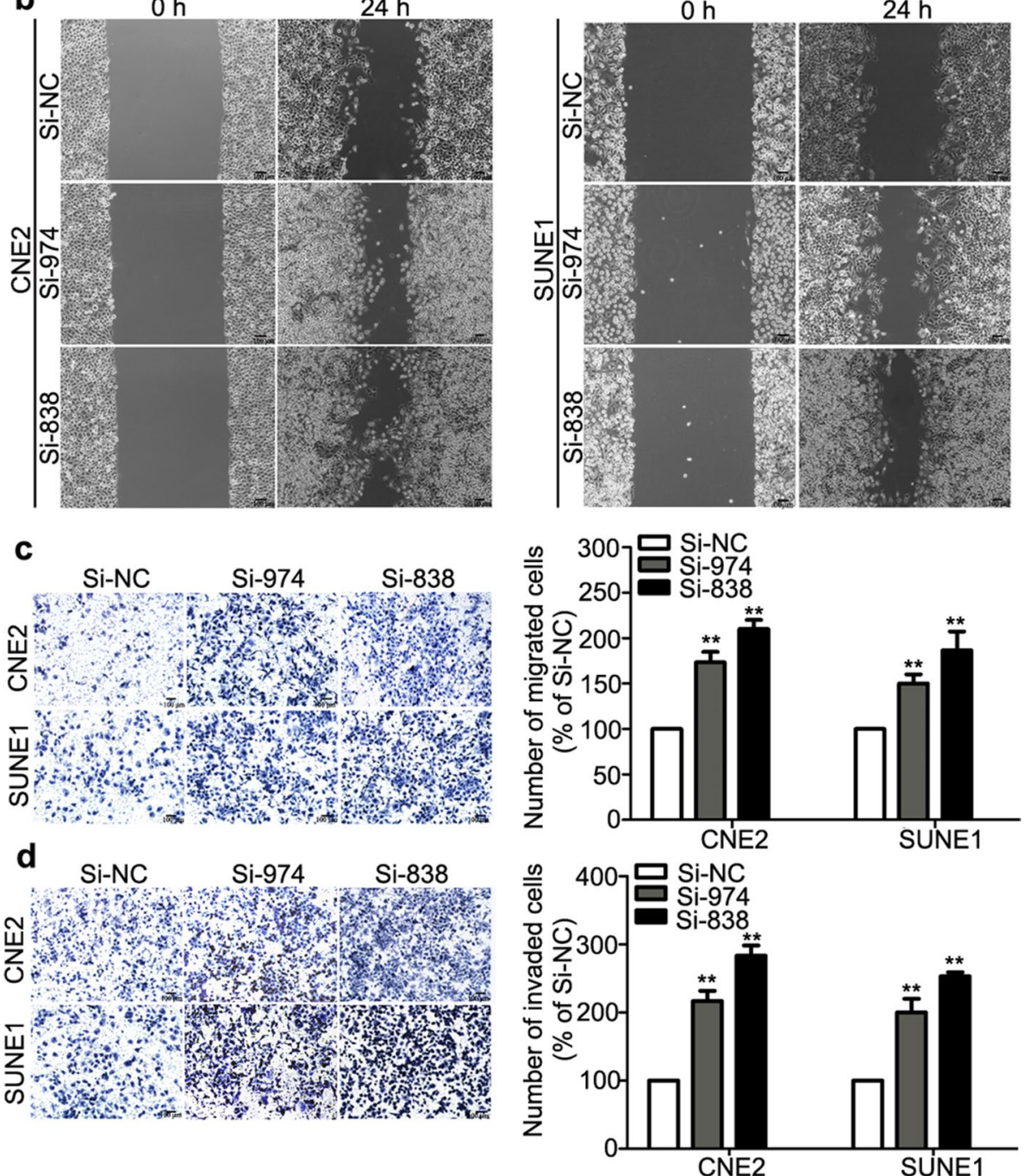

Fig. 3 Effects of YPEL3 silencing on NPC cell migration and invasion in vitro. a Representative western blotting analysis of YPEL3 silencing in CNE-2 and SUNE-1 cells. GAPDH served as the loading control. b-d Representative images and quantification of the effects of YPEL3 silencing on the migratory and invasive abilities of CNE-2 and SUNE-1 cells as determined by wound healing (b), Transwell migration (c), and invasion assays (d). All of the experiments were performed at least three times. Data presented are the mean $\pm S D ;{ }^{* *} P<0.01$ compared with control using Student t-test 

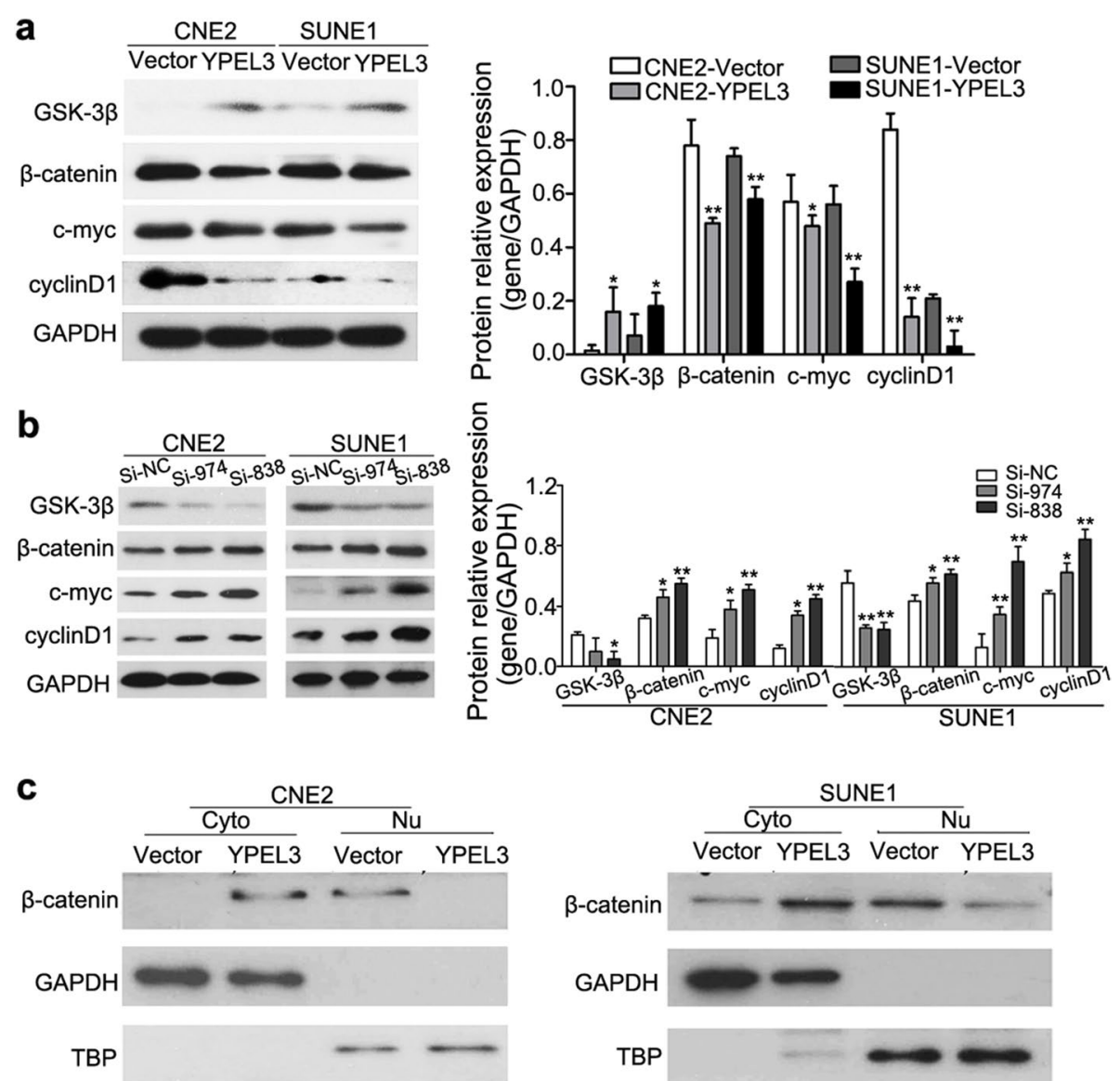

Fig. 6 YPEL3 inhibited the Wnt/ $\beta$-catenin signaling pathway. a Representative western blotting and quantification analysis of GSK-3 $\beta$, $\beta$-catenin, C-MYC, and cyclin D1 expression levels after YPEL3 overexpression. b Representative western blotting and quantification analysis of GSK-3 $\beta$, $\beta$ catenin, c-MYC, and cyclin D1 expression levels after YPEL3 silencing. cYPEL3 inhibited the nuclear (Nu) translocation of $\beta$-catenin. Cyto, cytoplasmic. All of the experiments were performed at least three times. Data presented are the mean $\pm \mathrm{SD} ;{ }^{*} P<0.05$ and ${ }^{* *} P<0.01$ compared with control using Student t-test 